Research Article

\title{
Determinants of work productivity among selected tertiary education employees: A PreCOVID-19 pandemic analysis
}

\author{
John Mark R. Asio \\ Gordon College, Philippines
}

\begin{abstract}
The work productivity of an individual is an organizational asset that can be equated to progress and success. It provides satisfaction to the employees, the organization, and other stakeholders. This study assessed the work productivity among selected employees from a tertiary education institution before COVID-19 pandemic. To accomplish this task, a total of 70 individuals participated in the survey with the use of the convenience sampling technique. This descriptive research study used an adapted and modified questionnaire from Buuri (2015) as a research instrument. For the statistical analysis, the study used SPSS 20 to compute and analyze the data. Results showed that the respondents came from both the administrative and faculty offices which belong to the age bracket of 21-30 years old; dominated by males and were single with 1-5 years in service. Based on their response, the respondents "agree" that they were productive in their work before the COVID-19 pandemic. Also, there were significant differences found in the work productivity when grouped according to demographic profiles. Furthermore, all the demographic profiles yielded direct and indirect relationship with work productivity. Regression analysis provided evidence that the department and sex were significant determinants of work productivity among employees. Based on the results, the researcher provided implications pertinent to the institution.
\end{abstract}

Keywords: Demographic profile, productivity of employees, tertiary education, COVID-19 pandemic, regression analysis, determinants and implications

\section{Introduction}

Being productive in the workplace is an integral part of the business in the organization. At the end of the working hour, the employees should produce and deliver quality outputs. However, when a crisis arises just like the current state of the pandemic that we are right now, this might change. In the advent of the current pandemic, work productivity provides different perspectives.

However, this study happened to be in course of data gathering before the pandemic took over. Thus, during the review of different literature, it focused on the context of non-pandemic ideas and perspectives. Most of the works of literature read for the work productivity tackled academic institutions (Nwinyokpugi et al., 2020; Moore e al., 2019; Kenny, 2017) and the impacts or effects of different variables like team management, productivity measurements, performance management. On the other hand, work productivity can also be affected by different factors which include the educational attainment of the worker (Vandenberghe, 2017; Sheehan \& Shi, 2019), gender (Tsuo \& Yang 2019), the external environment (Lasende et al., 2020) and even age (Gabriele et al., 2018).

Work productivity is also important in terms of providing sound and quality service to different stakeholders. In a related study, Giuliano et al., (2017) affirmed that corporate social

\section{Address of Corresponding Author}

John Mark R. Asio, Gordon College, Valenzuela St., Capitol View Park Subdivision,, Malolos, 3000 Bulacan, Philippines.

$\triangle$ asio.johnmark@gmail.com

0000-0002-6096-4595

How to cite: Asio, J. M. R. (2021). Determinants of work productivity among selected tertiary education employees: A PreCOVID-19 pandemic analysis. International Journal of Didactical Studies, 2(1), 101455. https:// doi.org/10.33902/IJODS. 2021167470 
responsibility (CSR) has certain benefits to productivity. However, to sustain a high impact and satisfaction guaranteed output, training is essential as revealed by Chetri et al., (2018) in their study where employer-sponsored training and workforce productivity relationship is multidimensional. Furthermore, some employees simply like to multitask therefore, a study by Tetteh and Attiogbe (2019) found that schooling and working at the same time results in less time for studies which affects academic performance negatively.

Furthermore, work productivity equates to different prospects that might help an economy like one study of Sheehan and Shi (2019) where enhancing education can have significant gains from low-income countries. Tsuo and Yang (2019) on the other hand tackled productivity in terms of different firms or industries. Furthermore, retirement plans (Gabriele et al., 2018) provides a negative impact on productivity. And finally, team and performance management also provides a certain degree of relationship to employee productivity (Nwinyokpugi et al., 2020; Kenny, 2017).

Productivity involves not only normal employees but also those with disabilities. Jammaers et al., (2016) discussed and identified three types of discursive practices that affect a person with a disability. Battaglio and French, (2016) mentioned that in their study the effect of organizational factors shows higher levels of self-sacrifice. We can apply concepts of productivity in any workplace like the study of Bhatia and Mahendru, (2014) wherein they showed that the foreign sector banks have the highest average for all the productivity parameters. On the lighter side, Karl et al., (2013) suggested that "you are what you wear" because wearing an attire influences one's productivity and personality. Satisfaction with nonmaterial job attributes affects perceived job productivity (Taylor et al., 2013). This result is very humbling to hear since more people value money than any other things, yet still, some individual's stay simple. Corsi and D'Ippoliti, (2013) concluded that investigating productivity in the public sector seems very useful for productive units.

Negative approaches also confront productivity like what Siltala, (2013) found, neglecting basic work affects the sense of self-efficacy of the employees. This unsettling result can affect the organization in several ways. Pendleton and Robinson, (2010) showed that stock plans need other methods of employee participation. Employee participation is very critical if an organization wants to meet its goals. With this idea at hand, selected HRD sub-systems found selected management styles to have a significant impact on HR effectiveness (Jain \& Prekumar, 2011).

The purpose of this study is to assess the demographic profiles and work productivity of selected employees from a tertiary education institution in Central Luzon, Philippines. At the same time, analyze the determinants of work productivity among the selected employees before the COVID-19 pandemic. This study can have a great impact on the educational service and how do they serve as leverage to satisfy both ends of the rope, the students, and the organization.

The result of this study will contribute highly to the growing literature of COVID-19 researches. Also, the researcher would like to add more reliable and credible information about this specific field but in a more localized perception and understanding. Policy-makers in the local areas can also benefit from this study to make a sound and research-based decision making. And finally, to create a more simplified insight on how each concept affects the other.

\section{Method}

\subsection{Research Design}

This study used a descriptive research design with the survey questionnaire as the principal instrument in gathering data. This study concerns the analysis of the work productivity of selected employees from a tertiary education institution in Central Luzon, Philippines. A descriptive design aims to assess or describe a certain issue or trend. Since the researcher would like to describe an issue related to the work productivity of employees thus; a descriptive method, technique is suitable for the job.

\subsection{Participants}

With the use of convenience sampling, a total of 70 participants participated in the survey from the original 100 targeted samples. The said survey covered the months of February 1 to March 15, 2020, before the total lockdown of institutions and facilities due to the COVID-19 pandemic. The study failed to meet the desired number of respondents due to different reasons like a busy schedule, lack of interest or limited time to answer, or something else. The participants were all bona fide employees from a tertiary education institution located in a particular province in Central Luzon, Philippines. To be included, they need to be working within the institution for at 
least a year before the participation in the survey. Table 1 shows the demographic profile of the respondents of the study.

Table 1

Demographic Profile of the Respondents

\begin{tabular}{lcc}
\hline & Frequency & Percentage \\
\hline Department & 35 & 50 \\
$\quad$ Administration & 35 & 50 \\
$\quad$ Faculty & & \\
Age & 29 & 41 \\
$21-30$ years old & 15 & 21 \\
31-40 years old & 17 & 24 \\
41-50 years old & 9 & 14 \\
51 years and above & & \\
Sex & 41 & 59 \\
Male & 29 & 41 \\
Female & 42 & 60 \\
Civil Status & 24 & 34 \\
$\quad$ Single & 4 & 6 \\
Married & & \\
Others & 51 & 73 \\
Years in Service & 11 & 16 \\
1-5 years & 8 & 11 \\
6-10 years & $\mathbf{7 0}$ & $\mathbf{1 0 0}$ \\
\hline Total and above & & \\
\hline
\end{tabular}

As can be seen on the first item of the demographic characteristics of the participants, the administrative personnel and the faculty have an equal number of respondents. On the second item, employees who belonged to the age bracket 21-30 years old dominated the other brackets. For the third item, the male-dominated female. For the fourth item, there are more single employees than the married and other status of civility. And for the last item, most of the employees have 1-5 years of service in the institution. This is a typical description of employees working in a tertiary education institution.

\subsection{Instrument}

For the instrument of the study, the researcher adopted and modified the Employee Productivity of Buuri (2015) that comprises 11 statements that tackle productivity. The instrument is composed of two parts, the first part is the demographic profile of the respondents and the second part is the employee productivity. The instrument underwent reliability and validity tests using Cronbach Alpha and the overall result of the reliability test was .81 , which is better than the .70 benchmark score. The researcher also pretested the instrument to students who were not part of the study to test its accuracy and understandability of the items before the actual survey.

\subsection{Data Analysis}

In this study, the researcher used frequency and percentage for the demographic profile, mean for the employee productivity, t-test, and ANOVA for the significant differences of the mean in the responses, and Regression Analysis for the determinants of work productivity. With the help of Microsoft Excel, the researcher tallied, tabulated, and classified the data. Furthermore, the analysis of data is through the use of SPSS 20 with the corresponding computation and interpretation. The researcher also patterned the values assigned to describe the work productivity of the employees after Likert Scaling.

\section{Results}

Table 2 shows the work productivity of the employees before the COVID-19 pandemic. As seen, the statement that got the highest mean score is item number 7 with a score of 3.26 with an interpretation of "agree" on the Likert scale. However, statement 5 got the lowest mean score with 2.70, still interpreted as "agree" on the Likert scale. The over-all mean is 3.05 with a Likert 
interpretation of "agree". This only shows that the respondents have high work productivity perceptions.

Table 2

Work Productivity of the Respondents before COVID-19 Pandemic

\begin{tabular}{|c|c|c|}
\hline Statement & Mean & Interpretation \\
\hline Employees' quality of work improves over time. & 3.04 & Agree \\
\hline Employees can deliver within the set deadlines. & 3.07 & Agree \\
\hline Employees have steadily increased their output. & 3.04 & Agree \\
\hline Employees can deliver under less than perfect conditions. & 2.79 & Agree \\
\hline Over time we have been able to reduce service cycle time. & 2.70 & Agree \\
\hline Employees provide suggestions to enhance their service delivery. & 3.04 & Agree \\
\hline $\begin{array}{l}\text { Employees are eager to learn ways of making themselves more } \\
\text { productive. }\end{array}$ & 3.26 & Agree \\
\hline $\begin{array}{l}\text { Over time we have increased customer satisfaction with the } \\
\text { quality service delivered. }\end{array}$ & 3.04 & Agree \\
\hline $\begin{array}{l}\text { Employees can generate more than an hours' worth of } \\
\text { productivity each hour. }\end{array}$ & 3.04 & Agree \\
\hline Employees have a sense of what to do and when to do it. & 3.09 & Agree \\
\hline $\begin{array}{l}\text { Employees are eager to maximize themselves to be more } \\
\text { productive. }\end{array}$ & 3.21 & Agree \\
\hline Employees can identify and give top attention to top priorities. & 3.21 & Agree \\
\hline Over-all Mean & 3.05 & Agree \\
\hline
\end{tabular}

Legend: 1.00-1.49=Totally Disagree; 1.59-2.49= Disagree; 2.50-3.49= Agree; 3.50-4.00= Totally Agree

Table 3 shows the significant differences in the responses for work productivity when grouped according to age, civil status, and years in service. There is a significant difference in the productivity of employees when grouped according to department and sex since the t-values were -2.983 and 2.685 which correspond to p-values of .004 and .010 respectively. Both results were significant at alpha .05 level of significance. This evidence shows that the department and the sex of the employees can be a significant factor in work productivity. We also observe significant evidence of differences in terms of civil status and years in service since they got F-values of 6.363 and 3.558 respectively. These correspond to p-values of .003 and .034 at the same time. Their Fvalues were significant at .05 alpha level of significance. Age did not yield a substantial degree of difference since the obtained F- value is 2.489 with a p-value of .068 which is higher than the alpha significance level of .05. This means that civil status and years in service can influence the work productivity of an employee. However, age is not a factor in determining the work productivity of an individual.

Table 3

Significant Differences in the Work Productivity of Selected Employees

\begin{tabular}{lcc}
\multicolumn{1}{c}{ Variables } & Work Productivity & $\boldsymbol{p}$-values \\
\hline Department & $-2.983^{*}$ & .004 \\
Age & $2.658^{*}$ & .010 \\
Sex & 2.489 & .068 \\
Civil Status & $6.363^{*}$ & .003 \\
Years in Service & $3.558^{*}$ & .034 \\
\hline
\end{tabular}

${ }^{*} p<.05$

Table 4 shows the relationships between the respondents' demographic profiles and productivity. As seen from the table, all five demographic profile variables produced substantial results to show both low-direct and indirect relationships. The following $r$-values for the department (.340), age (-.318), sex (-.307), civil status $(-.379)$, and years in service (-.302) correlated significantly with work productivity. All of the variables mentioned are significant at .05 alpha significance level. With these results, it is safe to assume that the five variables are factors that influence the work productivity of an employee in both positive and negative ways. 
Table 4

Correlation Matrix Between the Demographic Profile of the Respondents and Productivity

\begin{tabular}{lcccccc}
\hline & 1 & 2 & 3 & 4 & 5 & 7 \\
\hline 1) Department & 1 & & & & & \\
2) Age & $-.503^{*}$ & 1 & & & \\
& $(.000)$ & & & & \\
3) Sex & .203 & -.147 & 1 & & \\
& $(.092)$ & $(.223)$ & & & \\
4) Civil Status & $-.475^{*}$ & $.557^{*}$ & -.012 & 1 & & \\
& $(.000)$ & $(.000)$ & $(.919)$ & & & \\
$5)$ Years in Service & -.147 & $.304^{*}$ & .035 & $.336^{*}$ & 1 & \\
& $(.226)$ & $(.010)$ & $(.776)$ & $(.004)$ & & \\
6) Productivity & $.340^{*}$ & $-.318^{*}$ & $-.307^{*}$ & $-.379^{*}$ & $-.302^{*}$ & 1 \\
& $(.004)$ & $(.007)$ & $(.010)$ & $(.001)$ & $(.011)$ & \\
\hline
\end{tabular}

${ }^{*} p<.05$

Table 5

Regression Analysis for Demographic Profiles that Affect Productivity of Employees

\begin{tabular}{|c|c|c|c|c|c|}
\hline \multirow[t]{2}{*}{ Model } & \multicolumn{2}{|c|}{$\begin{array}{l}\text { Unstandardized } \\
\text { Coefficients }\end{array}$} & \multirow{2}{*}{$\begin{array}{c}\text { Standardized } \\
\text { Coefficients } \\
\text { Beta }\end{array}$} & \multirow[b]{2}{*}{$t$-value } & \multirow[b]{2}{*}{$p$-value } \\
\hline & B & Std. Error & & & \\
\hline (Constant) & 3.702 & .369 & & 10.021 & .000 \\
\hline Department & .318 & .144 & .274 & 2.217 & $.030^{*}$ \\
\hline Age & -.056 & .072 & -.104 & -0.781 & .438 \\
\hline Sex & -.440 & .123 & -.373 & -3.569 & $.001^{*}$ \\
\hline Civil Status & -.131 & .128 & -.136 & -1.025 & .309 \\
\hline Years in Service & -.146 & .093 & -.172 & -1.578 & .120 \\
\hline
\end{tabular}

Note: Constant $=3.702, F(5,64)=6.723,{ }^{*} p<.05, \mathrm{R}^{2}=.344$

Table 5 presents the statistics results of the regression analysis on the work productivity of employees and their potential demographic profile predictor. As deduced, the department and sex of the employees provided B coefficients lower than the Alpha significance of .05 levels. This only means that the department and sex are cogent predictors or determinants of employee work productivity.

For the multiple regression model, all the five predictors yielded $\mathrm{R}^{2}=.344, F(5,64)=6.723, p<$ .05. As observed from the table, the sex produced a negative $t$-value relationship, this means that the male is more productive. The department has a positive $t$-value which means the faculty is more productive. Other factors also correlated, but not to a significant extent. This means that the other demographic profiles like age, civil status, and years in service also account for the productivity of the employees.

\section{Discussion}

The objective of this study is to assess the demographic profiles and the work productivity of selected employees. Besides, it also analyzes the determinants of work productivity of selected employees in a tertiary education institution in Central Luzon, Philippines before the COVID-19 pandemic.

Based on the findings of the study, the demographic profile provided the following vital information: there were equal numbers of administrative personnel and faculty in the study. The age of the employees was between 21-30 years old which is still young. More males and singles in the group possess a working experience of 1-5 years. This is a typical setup of an organization where the employees are young, work-driven, results-oriented, and willing to gain more experience.

The result of the work productivity survey confirms a positive review. All of the items got an affirmative response from the respondents. This means that before the COVID-19 pandemic this is their perception about being a productive employee and an individual. Of course, the said result concurs with the ideas of Kovacs et al., (2019) where they introduced that work productivity behavior change systems help us decrease time on unproductive activities. 
The present study also subjected the data through statistical analysis and found some remarkable results. The work productivity of the respondents yielded pertinent outcomes and differences in the responses. The department, sex, civil status, and years in service came up with varying results from the respondents. This only means that even though the respondents work in the same institution, their work productivity differs from one context to another. This contradicted the results posited by Adedapo (2020) wherein the author revealed no significant difference in the academic staff productivity among universities, polytechnics, and colleges of education.

A deeper insight into the study includes determining the relationships among the demographic profile and productivity of employees, and the current study provided substantial scores. A relationship existed between the two variables. The result is parallel to the literature review of Heng et al. (2020) where personal and environmental factors affect research engagement and productivity. Also, gender plays a vital role in increasing productivity (Tsou \& Yang, 2019). But Laseinde et al (2020) pointed out that the external environment has a relationship with productivity.

In determining whether the demographic profiles of the respondents affect the work productivity of the employees, the current study also yielded significant findings. The result is somehow related to the findings of Kampelman et al (2018) where they stated that educational credentials have a greater impact on productivity which is more pronounced among younger workers and women. However, some studies argued with the current study like the perspective of Rombe (2016) where he found that time management has an inverse relationship with productivity in an organization and Kovacs et al., (2019) emphasized behavior change designers target individual productivity goals. Also, Adzovie et al. (2017) showed that Facebook can also influence employee productivity.

\section{Conclusion}

Based on the data and information gathered and treated, the researcher, therefore, concluded that: the respondents are from the administrative personnel and faculty; they are aged between 21-30 years, there are more males than females; most are still single, with 1-5 years in service. The work productivity of the respondents yielded an overall mean which corresponds to "agree" in the Likert Scale. There are significant findings in terms of productivity when respondents are grouped according to department, sex, civil status, and years in service. Also, there is evidence of a relationship with the five demographic profiles (department, age, sex, civil status, and years in service) which correlated directly and indirectly with productivity. To determine the work productivity of employees, the department and sex are the positive and negative factors.

Just like other studies, this one is no exception for its limitations. The first limitation of this study is the setting since it is only done in just one particular institution; it is highly advisable to do it in several academic institutions in a broader perspective. Second, the respondents, since the study was done in a brief amount of time, the number of respondents was not met. Some respondents did not return the survey because of their busy schedule and workload. Last, the method, it is suggested to triangulate the quantitative results with qualitative remarks of other respondents to strengthen the result of the study. Therefore, a mixed form of research design is suggested.

\subsection{Implications}

Based on the information that was generated from the study, the researcher suggested the following implications for the study. The institution should explore the possibility of shortening the working days in a week and longer working hours for the day to provide a longer time for rest and leisure. Through this measure, the employee can maximize his/ her working schedules and can provide better service by shorter working days but longer hours, and no need for overtime. The institution can also save and profit from such a scheme. Another suggestion could work in a flexible time (flexi-time) if some faculty members or personnel can avail or intend to use it. Since the locale of the study is an educational institution (or a college), such a suggestion is possible. The administration should also promote organizational commitment, trust, and loyalty since every employee is guided by the organization's vision, mission, and goals. There should also be a plausible reward/ incentive system so that faculty and personnel can enjoy and see their significance in the organization. Last, future studies may also explore other potential roles of work productivity of personnel in comparison to other institutions or set-ups. 


\section{References}

Adedapo, A.A. (2020). Recruitment and job security as correlates of academic staff productivity in tertiary institutions in Southwest, Nigeria. Euro Afro Studies International Journal, 2(1), 24-33. https://doi.org/10.5281/zenodo.3969780

Adzovie, D.E., Nyieku, I.E., \& Keku, J.A. (2017). Influence of Facebook usage on employee productivity: A case of university of cape coast staff. African Journal of Business Management, 11(6), $110-116$. https://doi.org/10.5897/AJBM20117.8265

Battaglio, R.P., Jr, \& French P.E. (2016). Public service motivation, public management reform, and organizational socialization: testing the effects of employment-at-will and agency on PSM among municipal employees. Public Personnel Management, 45 (2), 123-147. https://doi.org/10.1177/ 0091026016644623

Bhata, A., \& Mahendru, M. (2014). A comparative study of labor productivity in public, private, and foreign banks in India. Asia-Pacific Journal of Management Research and Innovation, 10 (3), 239-251. https://doi. org/ 10.1177/2319510X14539741

Buuri, D.W. (2015). Performance measurement practices and employee productivity in the insurance firms in Kenya. [Master's Thesis, University of Nairobi]. http:/ /hdl.handle.net/11295/94455

Chhetri, P., Gekara, V., Manzoni, A., \& Montague, A. (2018). Productivity benefits of employer-sponsored training: A study of the Australian transport and logistics industry. Education + Training, 60(9), 10091025. https://doi.org/10.1108/ET-02-2017-0029

Corsi, M., \& D'Ippoliti C., (2013). The productivity of the public sector: a Classical view. PSL Quarterly Review, 66 (267), 403-434.

Gabriele, R., Tundis, E., \& Zaninotto, E. (2018). Aging workforce and productivity: the unintended effects of retirement regulation in Italy. Economia Politica, 35, 163-182. https://doi.org/10.1007/s40888-01700079-x

Giuliano, R., Mahy, B., Rycx, F., \& Vermeylen, G. (2017). Does corporate social responsibility make overeducated workers more productive? Applied Economics 49(6), 587-605. https://doi.org/10.1080/ 00036846.2016.1203061

Heng K., Hamod, M.O., \& Khan, A. (2020) Factors influencing academics' research engagement and productivity: A developing countries perspective. Issues in Educational Research 30(3), 965-986. http://www.iier.org.au/iier30/heng.pdf

Jain, R., \& Premkumar, R., (2011). HRD practices in Indian organizations and their impact on 'productivity' of human resources: an empirical study. Management and Labour Studies. 36 (1), 5-30. https://doi.org/ 10.1177/0258042X1103600101

Jammaers, E., Zanoni, P., \& Hardonk, S., (2016). Constructing positive identities in ableist workplaces: disabled employees' discursive practices engaging with the discourse of lower productivity. Human Relations, 69 (6), 1365-1386. https://doi.org/10.1177/0018726715612901

Kampelmann, S., Rycx F., Saks, Y., \& Tojerow, I. (2018). Does education raise productivity and wages equally? The moderating role of age and gender. IZA Journal of Labor Economics, 7(1), 1-37. https://doi.org/10.1186/s40172-017-0061-4

Karl, K.A., Hall, L.M., \& Peluchtte, J.V., (2013). City employee perceptions of the impact of dress and appearance: you are what you wear. Public Personnel Management, 42 (3), 452-470. https://doi.org/ $10.1177 / 0091026013495772$

Kenny, J. (2017). Academic work and performativity. Higher Education 74, 897-913. https://doi.org/10.1007/s10734-016-0084-y

Kovacs, G., Gregory, D.M., Ma, Z., Wu, Z., Emami, G., Ray, J., \& Bernstein, M.S. (2019). Conservative of procrastination: Do productivity interventions save time or just redistribute it? In Proceedings of ACM CHI Conference on Humanitarian Factors in Computing Systems (CHI 2019), 330. https://doi.org/10.1145 /3290605.3300560

Laseinde, T., Oluwafemi, I., Pretorius, J.H., Oluwafemi, J. (2020). The impact of a work environment in concurrence to productivity in higher institutions. In: Goossens R., Murata A. (eds) Advances in Social and Occupational Ergonomics. AHFE 2019. Advances in Intelligent Systems and Computing, 970. Springer, Cham. https://doi.org/10.1007/978-3-030-20145-6_31

Moore, K., Coates, H., \& Croucher, G. (2019). Investigating applications of university productivity measurement models using Australian data. Studies in Higher Education, 44(12), 2148-2162. https://doi.org/10.1080/03075079.2018.1479846

Nwinyokpugi, P.N., \& Ebietuoma, S.T. (2020). Work team management; a recipe for tertiary institutions' productivity in Delta State, Nigeria. International Journal of Social Science and Human Research, 3(5), $27-$ 38. https://ijsshr.in/v3i5/Doc/1.pdf

Pendleton, A., \& Robinson, A. (2010). Employee stock ownership, involvement, and productivity: An interaction-based approach. Industrial and Labor Relations Review, 64 (1), 3-29. https:/ / doi.org/10.1177/001979391006400101

Rombe, M.L.M. (2016). Effective time and self-management, environment, and productivity in an organization. Science Journal of Business and Management, 4(6), $204-211$. https://doi.org/10.11648/j.sjbm.20160406.15 
Sheehan, P., \& Shi, H. (2019). Employment and productivity benefits of enhanced educational outcomes: A preliminary modeling approach. Journal of Adolescent Health, 65(1), S44-S55. https://doi.org/10.1016/ j.adolhealth.2019.03.025

Siltala, J. (2013). New public management: the evidence-based worst practice? Administration \& Society. 45(4), 468-493. https://doi.org/10.1177/0095399713483385

Taylor, J., Steel, B.S., \& Simon, C.A. (2013). The influence of job attributes and culture on job productivity: comparing the views of public servants in the Asia Pacific and the United States. Review of Public Personnel Administration, 33 (2), 205-224. https://doi.org/10.1177/0734371X13484828

Tetteh, E.N., \& Attiogbe, E.J.K. (2019). Work-life balance among working university students in Ghana. Higher Education, Skills and Work-Based Learning, 9(4), 525-537. https://doi.org/10.1108/HESWBL-082018-0079

Tsuo, M-W., \& Yang, C-H. (2019). Does gender structure affect firm productivity? Evidence from China. China Economic Review, 55, 19-36. https://doi.org/10.1016/j.chieco.2019.03.005

Vandenberghe, V. (2017). The productivity challenge. What to expect from better-quality labor and capital inputs? Applied Economics 49(40), 4013-4025. https:/ / doi.org/ 1080/00036846.2016.1273504 